\title{
Comparison of dantrolene sodium and diazepam in the treatment of spasticity
}

\author{
R. T. SCHMIDT, R. H. LEE, AND R. SPEHLMANN ${ }^{1}$ \\ From the Department of Neurology, Northwestern University Medical School; and \\ Neurology Service, Veterans Administration Lakeside Hospital, Chicago, Illinois, U.S.A.
}

SYNOPSIS The effects of dantrolene sodium and diazepam were compared in a double blind crossover study of 42 patients with spasticity due to stable multiple sclerosis. Both drugs reduced the findings of spasticity, clonus, and hyperreflexia, and the complaints of muscle stiffness and cramping. Each drug had different side effects which suggest indications and contraindications for its use in spastic patients.

Spasticity occurs in many neurological disorders, and is very common in multiple sclerosis. Although the mechanisms underlying spasticity are poorly understood (Landau, 1974), we are faced with the need to treat it when it becomes disabling. The indications for particular forms of treatment depend upon many factors (Nathan, 1970; Landau, 1974), but drug therapy is usually preferable to surgery in patients who retain some motor function in the lower extremities. From the drugs used to treat spasticity diazepam has emerged during the past decade as the most important agent (Wilson and McKechnie, 1966; Peirson et al., 1968; Nathan, 1970; Corbett et al., 1972). Its usefulness is often restricted by the side effects of sedation and aggravation of existing ataxia or weakness (Nathan, 1970; Lenman, 1971). In the search for more effective treatment of spasticity the gamma amino butyric acid derivative baclofen has recently been investigated (Pedersen et al., 1970; Burke et al., 1971; Cartlidge et al., 1974; Pedersen et al., 1974; From and Heltberg, 1975). Controlled studies (Cartlidge et al., 1974; From and Heltberg, 1975) comparing the effects of baclofen and diazepam on spasticity in two series of patients, most of whom had multiple sclerosis, found no significant differences between

1 Address for correspondence: Dr R. Spehlmann, VA Lakeside Hospital, 333 East Huron Street, Chicago, Illinois 60611, U.S.A. (Accepted 12 November 1975.) the two drugs. Sedation and weakness were fre quent side effects of both drugs at the doseso needed to reduce spasticity. Weakness was also an prominent side effect in another study of the spasmolytic effect of baclofen (Pedersen et al.o 1970). Recently another drug, dantrolene sodium was introduced to the treatment of spasticity (Chyatte et al., 1971; Herman et al., 1972 Basmajian and Super, 1973; Chyatte and Basmajian, 1973; Clinical Investigators' Manual, 1973; Gelenberg and Poskanzer, 1973; Mayer et al., 1973; Chipman et al., 1974; Ladd et al., 1974). In contrast with diazepam and baclofen, dantrolene promised the advantage of a drug acting directly upon the muscle by inhibiting the contractile mechanism (Clinical Investigators' Manual, 1973; Ellis and Bryant, 1972; Ellis and Carpenter, 1972), while having only few central effects. However, it is clear that the action of dantrolene can be detrimental clinically; while it reduced the useless power of spasticity, it also reduced the useful strength of volitional movement (Chyatte et al., 1971; Chyatte and Basmajian, 1973; Gelenberg and Poskanzer, 1973; Landau, 1974). Because strength was often already diminished by the condition leading to spasticity, weakness was usually the limiting factor in the treatment of spasticity with dantrolene. Although the available reports suggest that at least as many patients might benefit from this drug as from agents acting centrally, no con- 
trolled comparisons between dantrolene and such agents have as yet been made.

Our study was undertaken to compare the effects of dantrolene with those of diazepam in order to study the benefits and side effects in the same group of patients and thus to refine the indications for each agent. We conducted a double blind crossover study using dantrolene and diazepam in patients partially disabled by spasticity due to multiple sclerosis. In particular we wished to (1) compare quantitatively changes in physical functions produced by the two drugs; (2) compare the incidences of subjective improvement, deterioration, and side effects; (3) determine the ultimate drug and dose preferences of the patients; and (4) assess the usefulness of these drugs in patients with multiple sclerosis. We chose to evaluate the drug effects not only by physical examination of the patients, but also by recording their reports of changes in activities of daily living. This seems necessary for determining the overall effect (Chyatte and Basmajian, 1973; Gelenberg and Poskanzer, 1973) because a reduction of spasticity is not necessarily the most important parameter, especially when patients are hampered by neurological difficulties in addition to spasticity and when a drug has subjective side effects. Conversely, evaluation by subjective data alone is open to obvious criticism, and placebo effects are common in treating spasticity (Chyatte et al., 1971; Ladd et al., 1974).

\section{METHODS}

PATIENTS Participants were selected from the approximately 250 outpatients regularly attending the Northwestern University Multiple Sclerosis Clinic. Only patients with moderate or severe spasticity, which by history and examination clearly interfered with their physical function, were entered into the study. Anyone with severe dementia, ataxia, or tremor was excluded because testing would have been difficult. An attempt was made to select mainly ambulatory patients without severe lower extremity weakness despite their spasticity. The disability status scale grades of the patients together with a brief description (modified after Kurtzke (1965)), are shown in Table 1. Forty-two of 46 patients completed the study; four withdrew because of side effects or unrelated reasons. Each patient's general condition and symptomatology had remained basically stable for at least six months, and no ACTH or
TABLE 1

DISABILITY STATUS SCALE OF 42 PATIENTS

\begin{tabular}{clc}
\hline Grade & \multicolumn{1}{c}{ Description } & $\begin{array}{c}\text { Patients } \\
\text { (no.) }\end{array}$ \\
\hline 2 & Minimal disability & 4 \\
3 & Moderate disability, fully ambulatory & 4 \\
4 & Severe disability, fully ambulatory & 1 \\
5 & Ambulation limited unaided & 4 \\
6 & Canes, etc., required to ambulate & 17 \\
7 & Wheelchair, can transfer & 11 \\
8 & Bedridden, uses arms & 1 \\
\hline
\end{tabular}

TABLE 2

DRUG DOSAGE SCHEDULES

\begin{tabular}{cccc}
\hline \multirow{2}{*}{ Day } & $\begin{array}{c}\text { Capsule } \\
\text { and frequency }\end{array}$ & \multicolumn{2}{c}{ Daily dose of } \\
\cline { 3 - 4 } & & Dantrolene $(\mathrm{mg})$ or & Diazepam $(\mathrm{mg})$ \\
\hline $1-4$ & X 2 daily & 50 & 4 \\
$5-8$ & X 4 daily & 100 & 8 \\
$9-14$ & Y 4 daily & $200^{*}$ & $12^{*}$ \\
$15-28$ & Z 4 daily & $300 \dagger$ & $20 \dagger$ \\
\hline
\end{tabular}

* Low study dose. † High study dose.

corticosteroids had been used during that period. Those individuals who had been taking muscle relaxants or sedatives discontinued these at least two weeks before the study.

PROCEDURE Each patient was evaluated by the same examiner under two control and four treatment conditions, at consecutive two week intervals. After an initial control evaluation, a patient took either dantrolene or diazepam, selected randomly as the first drug, according to a fixed dosage schedule in three increments over a two week period. At this point a patient was again evaluated, after which he took a high dose for two weeks, followed by another evaluation (Table 2). The first drug was discontinued for a two week 'washout' period, during which the patient's condition returned to pretreatment level, and the same pattern was repeated for the other drug. Each patient was thus evaluated under the following six conditions: (1) control for the first drug; (2) low dose of first drug; (3) high dose of first drug; (4) control for second drug; (5) low dose of second drug; (6) high dose of second drug. The usual low and high doses at points of evaluation were dantrolene 25 and $75 \mathrm{mg}$ four times daily and diazepam 2 and $5 \mathrm{mg}$ four times daily. It became necessary to reduce drug 
TABLE 3

DRUG DOSES

\begin{tabular}{ccc}
\hline \multirow{2}{*}{ Capsule size } & \multicolumn{2}{c}{ Capsule contents } \\
\cline { 2 - 3 } & Dantrolene $(\mathrm{mg})$ or Diazepam $(\mathrm{mg})$ \\
\hline X & 25 & 2 \\
Y & 50 & 3 \\
Z & 75 & 5 \\
\hline
\end{tabular}

doses for 15 of the 42 patients when they reported side effects. With all patients, however, a substantial increment was maintained between the low and high doses used for evaluation.

Both drugs were contained in similar capsules labelled $X, Y$, and $Z$ with contents as shown in Table 3. Drug identities remained unknown to the patient, examiners, and other personnel participating in the study until its completion. The doses used in this study were chosen so that the high dose of each drug approximated the average maintenance dose reported to be optimal in previous studies involving non-ambulatory patients (Peirson et al., 1968; Mayer et al., 1973). If side effects on the first drug necessitated dose reduction, the second drug was reduced proportionately.

Two neurologists each evaluated half of the patients through the study. An evaluation consisted of two parts. First, an interim history was obtained with a standardized survey of pertinent symptoms in which the patient indicated any subjective improvement or deterioration compared with baseline. Reports of changes while on the two drugs were compared with chi-squared tests. Second, the following 10 physical functions were examined and graded quantitatively: spasticity, deltoid strength, hip flexor strength, station stability, hand coordination, hand speed, foot speed, stretch reflexes, clonus, and walking speed. Spasticity of the four limbs was estimated from the resistance to passive stretch, and clonus and reflexes were tested with standard clinical methods; those functions were graded zero (absent) to five (marked). The remaining six functions were determined using methods identical with those of the ACTH Cooperative Study (Rose et al., 1968; Rose et al., 1970). These methods require relatively simple mechanical equipment and yield reproducible values (Kuzma et al., 1965; Tourtellotte et al., 1965; Kuzma et al., 1969). From the results of each evaluation a score was calculated for a particular function by summing individual values measured for right and left sides and multiple trials. The scores obtained under the different experimental conditions in a functional category were compared using paired Student's $t$ tests.

After completion of the study and withdrawal from the second drug for a final two week period, each patient was again interviewed by his examiner and asked whether or not he would like to resume treatment with either of the two drugs. Those who chose to resume treatment with one of the drugs were asked to indicate the dose they found most helpful, according to the drug code being used in the study. In essence, each patient could indicate a preference for drug one or drug two, capsule size $X$, $\mathrm{Y}$, or $\mathrm{Z}$ and a frequency of one to four capsules daily. When requested to do so by the patient, the examining neurologist supplied information previously reported by that patient, including side effects and benefits experienced at various times during the study, but the examiner participated in the decisions as little as possible. Only when a drug and dose had been chosen was the drug code broken.

\section{RESULTS}

The numerical scores are shown in Table 4, while the statistical comparisons between drugs are shown in Table 5. Both dantrolene and $\stackrel{\AA}{\circ}$ 음 diazepam reduced spasticity, clonus, and reflexes ${ }^{\circ}-$ at low and high doses compared with controlo measurements. These functions were reduced significantly more by the high dantrolene doseô. $\overrightarrow{0}$ than by the low dose, whereas the two doses of diazepam had similar effects. At high doses, dantrolene and diazepam were equally effective against spasticity and clonus, but at both high and low doses dantrolene reduced reflexes to a greater extent than did diazepam. Dantrolene at high and low doses produced weakness of deltoids and hip flexors, but diazepam produced no deltoid weakness and produced hip flexor weakness at the high dose only. Diazepam at both doses decreased hand coordination, at high doses reduced hand speed, and at low doses decreased walking speed. The reduction in walking speed with high doses of diazepam did not reach significance $(P>0.10)$. Dantrolene did not impair any of these functions. Station stability deteriorated at the high dose of diazepam, but improved at the high dose of dantrolene. Foot speed was not altered by either drug.

The information provided by the survey of symptoms is summarized in Table 6. Improvement was reported by substantial proportions of patients mainly in two categories: (1) muscle 
TABLE 4

QUANTITATIVE RESULTS OF PHYSICAL FUNCTION EVALUATIONS ON LOW (LO) AND HIGH (HI) DOSES OF DANTROLENE SODIUM (DS) AND DIAZEPAM (DZ)

\begin{tabular}{|c|c|c|c|c|c|c|}
\hline \multirow[t]{2}{*}{ Category } & \multicolumn{6}{|c|}{ Mean scores } \\
\hline & Lo $D S$ & $H i D S$ & $\begin{array}{c}\text { Control } \\
D S\end{array}$ & Lo $D Z$ & $H i D Z$ & $\begin{array}{c}\text { Control } \\
D Z\end{array}$ \\
\hline Spasticity & 10.00 & 9.54 & 10.90 & 9.40 & 9.14 & 10.70 \\
\hline Deltoid strength & 48.50 & 47.45 & 51.62 & 49.64 & 50.16 & 49.33 \\
\hline Hip flexor strength & 119.66 & 122.19 & 142.59 & 156.43 & 126.51 & 151.31 \\
\hline Hand coordination & 144.71 & 146.55 & 146.00 & 141.24 & 133.81 & 153.38 \\
\hline Station stability & 43.21 & 45.92 & 41.93 & 39.11 & 34.11 & 43.84 \\
\hline Hand speed & 238.31 & 249.60 & 240.47 & 239.21 & 227.35 & 240.81 \\
\hline Foot speed & 242.12 & 239.80 & 220.36 & 233.39 & 226.48 & 237.96 \\
\hline Reflexes & 20.52 & 19.43 & 24.50 & 22.50 & 22.07 & 23.81 \\
\hline Clonus & 3.77 & 3.15 & 5.13 & 3.50 & 3.41 & 5.26 \\
\hline Walking speed & 11.33 & 10.56 & 10.82 & 13.81 & 17.12 & 10.73 \\
\hline
\end{tabular}

TABLE 5

STATISTICAL COMPARISON OF PHYSICAL FUNCTION SCORES: LEVEL OF SIGNIFICANCE AND DIRECTION OF CHANGE DURING TREATMENTS WITH LOW (LO) AND HIGH (HI) DOSES OF DANTROLENE SODIUM (DS) AND DIAZEPAM (DZ)

\begin{tabular}{|c|c|c|c|c|c|c|c|c|c|}
\hline \multirow[t]{2}{*}{ Category } & \multicolumn{9}{|c|}{ Diazepam $(D Z)$} \\
\hline & $\begin{array}{c}\text { Lo DS } \\
\text { vs } \\
\text { Control }\end{array}$ & $\begin{array}{c}\text { Lo } D Z \\
\text { is } \\
\text { Control }\end{array}$ & $\begin{array}{c}\text { Lo } D S^{*} \\
\text { ts } \\
\text { Lo } D Z\end{array}$ & $\begin{array}{c}\text { Hi DS } \\
\text { es } \\
\text { Control }\end{array}$ & $\begin{array}{c}\text { Hi DZ } \\
\text { es } \\
\text { Control }\end{array}$ & $\begin{array}{c}H i D S^{*} \\
\text { vs } \\
H i D Z\end{array}$ & $\begin{array}{c}\text { Control DS } \\
\quad \text { es } \\
\text { Control } D Z\end{array}$ & $\begin{array}{l}\text { Lo DS } \\
\quad \text { vs } \\
H i D S\end{array}$ & $\begin{array}{c}\text { Lo } D Z \\
\text { es } \\
\text { Hi } D Z\end{array}$ \\
\hline Spasticity & $0.001 \downarrow$ & $0.001 \downarrow$ & NS & $0.001 \downarrow$ & $0.01 \downarrow$ & NS & NS & $0.01(\mathrm{Hi})$ & NS \\
\hline Reflexes & 0.001 & $0.01 \downarrow$ & $0.01(\mathrm{DS})$ & $0.001 \downarrow$ & 0.01 & $0.001(\mathrm{DS})$ & NS & $0.01(\mathrm{Hi})$ & NS \\
\hline Clonus & $0.001 \downarrow$ & 0.001 & NS & 0.001 & $0.001 \downarrow$ & NS & NS & $0.02(\mathrm{Hi})$ & NS \\
\hline Deltoid strength & 0.001 & NS & 0.05 (DS) & 0.001 & NS & $0.10(\mathrm{DS})$ & 0.05 & NS & NS \\
\hline Hip flexor strength & 0.01 & NS & $0.001(\mathrm{DS})$ & $0.02 \downarrow$ & NS & NS & NS & NS & $0.01(\mathrm{Hi})$ \\
\hline Hand coordination & NS & 0.01 & NS & NS & 0.001 & $0.01(\mathrm{DZ})$ & NS & NS & $0.01(\mathrm{Hi})$ \\
\hline Station stability & NS & NS & NS & 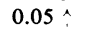 & $0.05 \hat{\imath}$ & 0.01 & NS & NS & $\mathrm{NS}$ \\
\hline Hand speed & NS & NS & NS & NS & 0.05 & NS & NS & NS & $0.01(\mathrm{Hi})$ \\
\hline Foot speed & NS & NS & NS & NS & NS & NS & NS & NS & NS \\
\hline Walking speed & NS & $0.01 \downarrow(\mathrm{DZ})$ & NS & NS & NS & NS & NS & NS & NS \\
\hline
\end{tabular}

NS: Not significant. $\quad \uparrow$ : Increased. $\quad \forall$ : Decreased. $\quad()$ : Dose or drug produced more change. * Compares change from control

cramps or spasms: dantrolene $60 \%$-diazepam $76 \%$; (2) stiffness: dantrolene $38 \%$-diazepam $48 \%$. Deterioration was reported mainly in regard to: (1) impaired gait: dantrolene $52 \%$ diazepam $75 \%$; (2) drowsiness: dantrolene $31 \%$-diazepam $67 \% ;(3)$ imbalance: dantrolene $17 \%$-diazepam $36 \%$; (4) incoordination: dantrolene $10 \%$-diazepam $29 \%$. None of these incidences of improvement and deterioration differed significantly for the two drugs in chisquared tests $(P>0.05)$. However, drowsiness, imbalance, and incoordination were reported significantly more often $(\mathrm{P}<0.05)$ on diazepam than on dantrolene when patients reporting the symptoms on both drugs were excluded from the comparison. Since any improvements and side effects were noted, in most cases, at both the high and low doses, we have not considered dosage in the analyses of symptoms.

When asked to select the preferred drug and its dose for continued treatment at the end of the study, 22 patients chose dantrolene at the daily dose of $118 \pm 54 \mathrm{mg}$ (mean \pm SD), 13 chose diazepam at a daily dose of $10.1 \pm 5.5 \mathrm{mg}$ and seven chose neither drug. The fact that 35 of 42 patients chose to continue taking a medication immediately after the study was probably partly a reflection of the enthusiasm of patient and medical staff. At six-month follow-up of these 35 patients, 11 were taking dantrolene, 12 diazepam, three both drugs, and nine neither drug; thus 23 of the 42 patients continued medication. Drug 
TABLE 6

SYMPTOM SURVEY: NUMBERS OF PATIENTS REPORTING CHANGES FROM BASELINE, IRRESPECTIVE OF DOSE

\begin{tabular}{|c|c|c|c|c|}
\hline & \multicolumn{3}{|c|}{ Changes from baseline (no.) } & \multirow{2}{*}{$\begin{array}{c}\text { Chi } \\
\text { squared } \\
B \text { vs. } C\end{array}$} \\
\hline & $\begin{array}{c}A \\
B o t h\end{array}$ & $\begin{array}{c}\text { B } \\
\text { Diazepam } \\
\text { only }\end{array}$ & $\begin{array}{c}C \\
\text { Dantrolene } \\
\text { only }\end{array}$ & \\
\hline \multicolumn{5}{|l|}{ A. Improved } \\
\hline Cramps, spasms & 17 & 4 & 8 & NS \\
\hline Stiffness & 10 & 10 & 6 & NS \\
\hline Gait & 2 & 4 & 5 & NS \\
\hline \multicolumn{5}{|l|}{ Bladder urgency, } \\
\hline incontinence & 1 & 1 & 3 & NS \\
\hline Dizziness, vertigo & 0 & 1 & 3 & NS \\
\hline Strength & 0 & 2 & 1 & NS \\
\hline Coordination & $\mathbf{0}$ & 1 & 2 & NS \\
\hline Balance & 0 & 1 & 1 & NS \\
\hline Drowsiness & 0 & 0 & 2 & NS \\
\hline \multicolumn{5}{|l|}{ B. Deteriorated } \\
\hline Strength & 22 & 10 & 6 & NS \\
\hline Drowsiness & 10 & 18 & 3 & $P<0.01$ \\
\hline Gait & 18 & 9 & 4 & NS \\
\hline Coordination & 2 & 10 & 2 & $P<0.05$ \\
\hline Imbalance & 7 & 8 & 0 & $P<0.01$ \\
\hline Fatigue & 2 & 6 & 3 & NS \\
\hline Cramps, spasms & 2 & 4 & 4 & NS \\
\hline \multicolumn{5}{|l|}{ Bladder urgency, } \\
\hline incontinence & 0 & 4 & 5 & NS \\
\hline Dizziness, vertigo & 5 & 3 & 3 & NS \\
\hline Diarrhoea & 2 & 0 & 4 & NS \\
\hline Headache, nausea & $\mathbf{0}$ & $\mathbf{0}$ & 1 & NS \\
\hline
\end{tabular}

doses at the time of follow-up were generally the same or similar to the dose chosen at the end of the study. However, some patients had individualized their treatment regimes or used combinations of drugs. We are uncertain as to the influence exerted in those decisions by the physicians treating the patients after the completion of the study. Table 7 shows the drug and dose preferences, along with the disability status scale score of each patient. Most patients selecting dantrolene chose a relatively low dose to minimize side effects. There was a significant negative Spearman's rank correlation ( $\mathrm{rs}=$ $-0.57, \mathrm{P}<0.01$ ) between the dantrolene doses and the disability scores, indicating that patients with greater disability chose lower doses of dantrolene. There was no significant correlation ( $r s=0.27, \quad P>0.05)$ between the doses of diazepam chosen and the disability scores, nor was there a correlation between the doses of either drug and the patients' body weight, hip flexor strength, or spasticity severity.

\section{DISCUSSION}

These results confirm that both dantrolene ando

TABLE 7

DRUG SELECTION AT END OF STUDY, AND DISABILITY SCORE

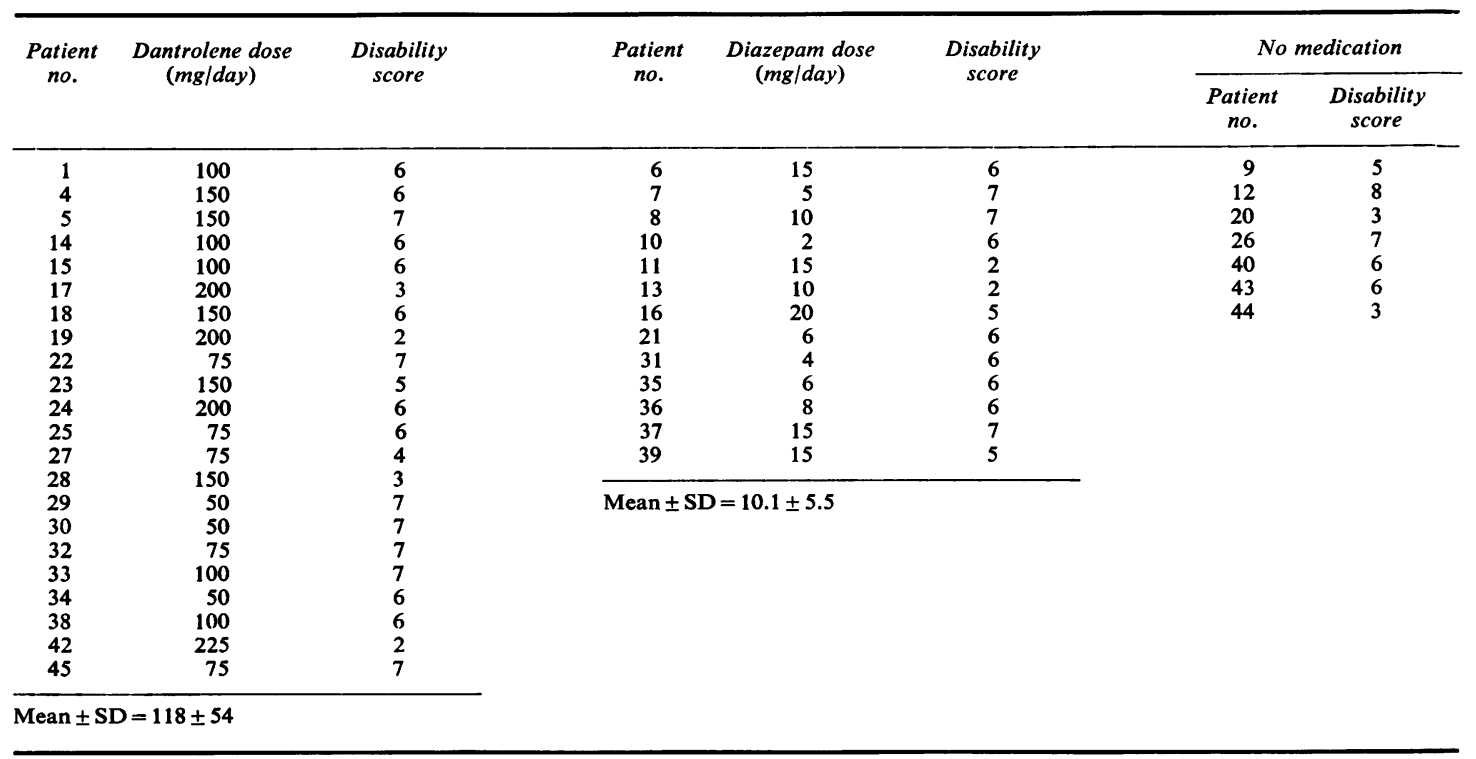


diazepam can relieve spasticity, clonus, and hyperreflexia in patients with multiple sclerosis. Although our study dealt only with patients having multiple sclerosis, there is no reason to believe that the results are not representative of spasticity of other causes, especially as none of our patients had active multiple sclerosis. At the doses used in this study, the two drugs appeared about equally effective against spasticity and clonus, but hyperreflexia was reduced more by dantrolene than by diazepam. This confirms the statements (Landau, 1974) that reflex activity is not a reliable indicator of spasticity, at least in the evaluation of drug effects. Neither drug improved hand coordination, hand speed, foot speed, or walking speed, but high doses of dantrolene improved station stability.

Weakness in all four extremities accompanied the antispastic action of dantrolene both at high and at low doses, whereas diazepam produced weakness only at high doses and only in the lower extremities. Weakness has been reported as a side effect of dantrolene in previous studies, yet we were impressed with the frequency and severity of weakness and the complaints of drowsiness and gait deterioration. Some patients began to fall because their legs buckled due to muscle weakness. Weakness lasted throughout the two week medication period. In spite of the severe weakness induced by dantrolene in many patients, station stability improved on average at the high doses of this drug. Furthermore, the observations on weakness made on physical examination contrast with the reports from the patients; more patients complained of weakness while on diazepam than while on dantrolene. It is not likely that they meant drowsiness and incoordination when they reported weakness while on diazepam because these categories were thoroughly explained to them. Therefore, our results indicate that weakness of subjectively important degree was produced more often by diazepam than by dantrolene, but that overall the measurable weakness produced by dantrolene exceeded that of diazepam. This suggests that dantrolene can be a very useful drug for treatment of spasticity in those patients in whom it did not produce significant weakness, and it would explain why many patients elected to be treated with dantrolene at the end of the study.

Diazepam produced measurable deterioration of hand coordination, hand speed, station stability, and walking speed. On the symptom survey, complaints of incoordination, imbalance, and drowsiness were frequent with diazepam. Dantrolene, in contrast, produced fewer of these complaints and no worsening of these functions on physical examination. It improved the patient's ability to maintain balance when standing without using the arms for support (station stability). Although at the beginning of the study none of the patients showed severe ataxia, most had obvious signs of impaired cerebellar function. Our findings suggest that diazepam produced deleterious effects not only from drowsiness, but also from further impairment of cerebellar function. This hypothesis is supported by an experimental study in mice (Ellis and Carpenter, 1974) indicating that dantrolene induces muscle relaxation at doses which do not impair motor coordination, whereas diazepam, chlordiazepoxide, and meprobamate do not produce muscle relaxation without first producing impairment of coordination.

The fact that a larger proportion of patients chose to be treated with dantrolene immediately after the study suggested that this drug was more acceptable than diazepam when both drugs were used at doses lower than the high dose in the study. However, at six-month follow-up, the numbers of patients on the two drugs were about equal. Side effects had been very prominent with both drugs, particularly at high doses.

These observations offer some help in the selection of a suitable drug and dosage for treating spasticity in individual patients with multiple sclerosis. It would appear that patients who are easily sedated and patients with marginal cerebellar function may tolerate diazepam poorly, and in these cases dantrolene would be preferred. However, patients with borderline strength may tolerate even low doses of dantrolene poorly, and may find diazepam more acceptable. Obviously, the physician who decides to treat spasticity in a patient with multiple sclerosis must exercise careful clinical judgement in his choice and follow the patient's response to therapy closely. Even very low doses of these drugs can be effective against spasticity. Using a low initial dose and increasing it in small increments would seem to be desirable in most cases. Within these limits, we feel that dantrolene and 
diazepam can offer symptomatic relief of spasticity to carefully selected multiple sclerosis patients.

We thank Mrs Sue Blonsky, Miss Loretta Kay, Mrs Carol Richards, and Mrs Marguerite Smith of the Multiple Sclerosis Clinic for their help. This study was supported by a grant from Eaton Laboratories.

\section{REFERENCES}

Basmajian, J. W., and Super, G. A. (1973). Dantrolene sodium in the treatment of spasticity. Archives of Physical Medicine and Rehabilitation, 54, 60-64.

Burke, D., Andrews, C. J., and Knowles, L. (1971). The action of a GABA derivative in human spasticity. Journal of the Neurological Sciences, 14, 199-208.

Cartlidge, N. E. F., Hudgson, P., and Weightman, D. (1974). A comparison of baclofen and diazepam in the treatment of spasticity. Journal of the Neurological Sciences, 23, 17-24.

Chipman, M., Kaul, S., and Lambie, M. (1974). Efficacy of dantrolene sodium in the treatment of spasticity. Diseases of the Nervous System, 35, 427-431.

Chyatte, S. B., and Basmajian, J. V. (1973). Dantrolene sodium: long-term effects in severe spasticity. Archives of Physical Medicine and Rehabilitation, 54, 311-315.

Chyatte, S. B., Birdsong, J. H., and Bergman, B. A. (1971). The effects of dantrolene sodium on spasticity and motor performance in hemiplegia. Southern Medical Journal, 64, 180-185.

Clinical Investigators' Manual on Dantrolene Sodium (1973). Norwich Pharmacal Co.: Norwich, N.Y.

Corbett, M., Frankel, H. L., and Michaelis, L. (1972). A double blind, crossover trial of Valium in the treatment of spasticity. Paraplegia, 10, 19-22.

Ellis, K. O., and Bryant, S. H. (1972). Excitation-contraction uncoupling in skeletal muscle by dantrolene sodium. Archives of Pharmacology, 274, 107-109.

Ellis, K. O., and Carpenter, J. F. (1972). Studies on the mechanism of action of dantrolene sodium. Archives of Pharmacology, 275, 83-94.

Ellis, K. O., and Carpenter, J. F. (1974). A comparative study of dantrolene sodium and other skeletal muscle relaxants with the Straub tail mouse. Neuropharmacology, 13, 211214.

From, A., and Heltberg, A. (1975). A double-blind trial with baclofen (Lioresal) and diazepam in spasticity due to multiple sclerosis. Acta Neurologica Scandinavica, 51, 158166.

Gelenberg, A. J., and Poskanzer, D. C. (1973). The effect of dantrolene sodium on spasticity in multiple sclerosis. Neurology (Minneap.), 23, 1313-1315.

Herman, R., Mayer, N., and Mecomber, S. A. (1972). Clinical pharmaco-physiology of dantrolene sodium. American Journal of Physical Medicine, 51, 296-311.
Kurtzke, J. F. (1965). Further notes on disability evaluation in multiple sclerosis with scale modifications. Neurology (Minneap.), 15, 654-661.

Kuzma, J. W., Namerow, N. S., Tourtellotte, W. W., Sibley, W. A., Kurtzke, J. F., Rose, A. S., and Dixon, W. J. (1969). An assessment of the reliability of three methods used in evaluating the status of multiple sclerosis patients. Journal of Chronic Diseases, 21, 803-814.

Kuzma, J. W., Tourtellotte, W. W., and Remington, R. D. (1965). Quantitative clinical neurological testing. 2. Some statistical considerations of a battery of tests. Journal of Chronic Diseases, 18, 303-311.

Ladd, H., Öist, C., and Jonsson, B. (1974). The effect of Dantrium on spasticity in multiple sclerosis. Acta Neurologica Scandinavica, 50, 397-408.

Landau, W. M. (1974). Spasticity: the fable of a neurological demon and the emperor's new therapy. Archives of Neurology, 31, 217-219.

Lenman, J. A. R. (1971). Drugs in the management of spasticity. Developmental Medicine and Child Neurology, 13, 386-388.

Mayer, N., Mecomber, S. A., and Herman, R. (1973). Treatment of spasticity with dantrolene sodium. American Journal of Physical Medicine, 52, 18-29.

Nathan, P. W. (1970). Spasticity and its amelioration. Modern Trends in Neurology, 5, 41-59. Edited by $D$. Williams: Butterworths: London.

Pedersen, E., Arlien-Søborg, P., Grynderup, V., and $\omega^{\circ}$ Henriksen, O. (1970). GABA derivative in spasticityo [ $\beta$-(4-chlorophenyl)- $\gamma$-aminobutyric acid, Ciba 34.647-Ba Acta Neurologica Scandinavica, 46, 257-266.

Pedersen, E., Arlien-Søborg, P., and Mai, J. (1974). Th mode of action of the GABA derivative baclofen in humam spasticity. Acta Neurologica Scandinavica, 50, 665-680.

Peirson, G. A., Fowlks, E. W., and King, P. S. (1968). Long term follow-up on the use of diazepam in the treatment $\$$. spasticity. American Journal of Physical Medicine, 47, 14 149.

Rose, A. S., Kuzma, J. W., Kurtzke, J. F., Namerow, N. S유ำ Sibley, W. A., and Tourtellotte, W. W. (1970). Cooperative study in the evaluation of therapy in multiple sclerosis; ACTH vs. placebo. Final report. Neurology (Minneap.), 20, no. 5, pt 2.

Rose, A. S., Kuzma, J. W., Kurtzke, J. F., Sibley, W. A., and Tourtellotte, W. W. (1968). Cooperative study in the evaluation of therapy in multiple sclerosis; ACTH vs. placebo in acute exacerbations-preliminary report. Neurology (Minneap.), 18, no. 6, pt 2.

Tourtellotte, W. W., Haerer, A. F., Simpson, J. F., Kuzma, Э J. W., and Sikorski, J. (1965). Quantitative clinical neurological testing. 1. A study of a battery of tests designed to evaluate in part the neurological function of patients with multiple sclerosis and its use in a therapeutic trial. Annals of the New York Academy of Sciences, 122, 480-505.

Wilson, L. A., and McKechnie, A. A. (1966). Oral diazepam in the treatment of spasticity in paraplegia. A doubleblind trial and subsequent impressions. Scottish Medical Journal, 11, 46-51. 